\title{
ДИНАМИЧЕСКАЯ ЭФФЕКТИВНОСТЬ ВОСПРОИЗВОДСТВЕННЫХ ПРОЦЕССОВ НА РЕСУРСОДОБЫВАЮЩИХ ТЕРРИТОРИЯХ
}

\author{
Шарф Ирина Валерьевна', \\ irina_sharf@mail.ru
}

\author{
Михальчук Александр Александрович', \\ aamih@tpu.ru
}

\author{
Филимонова Ирина Викторовна, \\ filimonovaiv@list.ru \\ ' Национальный исследовательский Томский политехнический университет, \\ Россия, 635050, г. Томск, пр. Ленина, 30. \\ 2 Институт нефтегазовой геологии и геофизики им. А.А. Трофимука СО РАН, \\ Россия, 630090, г. Новосибирск, пр. ак. Коптюга, 3.
}

\begin{abstract}
Актуальность исследования обусловлена ухудшающимся состоянием ресурсной базы углеводородов в качественном и количественном плане. Позитивная динамика воспроизводства является основой нормального долгосрочного функционирования нестегазового комплекса и социально-экономического развития ресурсодобывающих регионов. В условиях отсутствия прямой функциональной зависимости в процессе воспроизводства необходимы методы исследования, которые позволяют выявить негативные факторы и тенденции на всех этапах воспроизводственного инвестиционного цикла, явившиеся следствием происходящих изменений на рынке углеводородов и в государственном регулировании недропользования.

Цель: проведение сравнительной оценки эффективности воспроизводственных процессов на ресурсодобывающих территориях с учетом построения экономико-математических моделей, основанных на применении непараметрических методов статистики. Объект: минерально-сырьевая база нефти ресурсодобывающих субъектов Российской Федерации. Методы: регрессионный, индекс производительности Малмквиста.

Результаты. Охарактеризованы общероссийские тенденции в воспроизводстве ресурсов и запасов нефти, отражающие факт количественного и качественного состояния минерально-сырьевой базы нефти. Представлена методика проведения исследования, базирующаяся на построении динамической эффективности, иллюстрирующей тенденцию рефлексии субъекта недропользования на изменения в макроэкономическом окружении и в системе недропользования в части налогового льготирования. Блочная модель инвестиционного цикла со следующими блоками - геолого-технологический, производственный, организационно-отраслевой, социально-экономический, бюджетный, финансово-налоговый - является методическим инструментарием оценки воспроизводственных процессов на всех этапах инвестиционного цикла, которая позволяет отразить взаимосвязь всех ключевых показателей развития нефтегазовой отрасли. Модельные расчеты позволили выявить наличие инвестиционного дестабилизатора, представляющего собой механизм совокупного влияния организационно-экономического механизма в недропользования в части налогового льготирования и ценовых параметров мирового рынка нефти. При этом наиболее действенное влияние наблюдается в Томской области.
\end{abstract}

Ключевые слова:

Нефть, запасы, индекс Малмквиста, динамическая эффективность, инвестиционный воспроизводственный цикл.

\section{Введение}

Основой долгосрочного конкурентного преимущества российской экономики на мировой арене является обеспеченность минеральными ресурсами. Кроме того, реализация стратегических задач по комплексному освоению и развитию регионов Российской Федерации неотъемлема от геологического изучения недр и воспроизводства ресурсов и запасов нефти.

В новейшей российской истории можно выделить следующие этапы в тенденциях добычи и воспроизводства запасов нефти и конденсата: 1991-1993 гг., когда прирост запасов превышал добычу в 1,2-2 раза; 1994-2005 гг., когда, наоборот, добыча превышала прирост запасов в 1,1-1,6 раза; 2006-2018 гг., когда возобновилась тенденция превышения прирощенных запасов над добытыми объемами (1-1,5 раза). Однако за последние три года наблюдалось только погашение добытых объемов нефти, что дает полное основание МПР РФ говорить о низкой обеспеченности «запасами разрабатываемых месторождений на период до 2035 года» [1. С. 5] (рис. 1), что подтверждается отнесением нефти ко второй группе полезных ископаемых, согласно утвержденной Правительством РФ Стратегии развития минеральносырьевой базы на период до 2035 г., так как «достигнутые уровни, добычи которых недостаточно обеспечены запасами разрабатываемых месторождений на период до 2035 года» [1. С. 4].

Вместе с тем, несмотря на растущую роль месторождений Восточной Сибири, высокая доля в добыче и приросте запасов нефти принадлежит старопромысловым районам Поволжья и Западной Сибири [2, 3]. Так, в 2018 г. из 55 месторождений углеводородного сырья (УВ), поставленных на государственный баланс, 39 месторождений, относящихся к категории мелких и мельчайших с сум- 


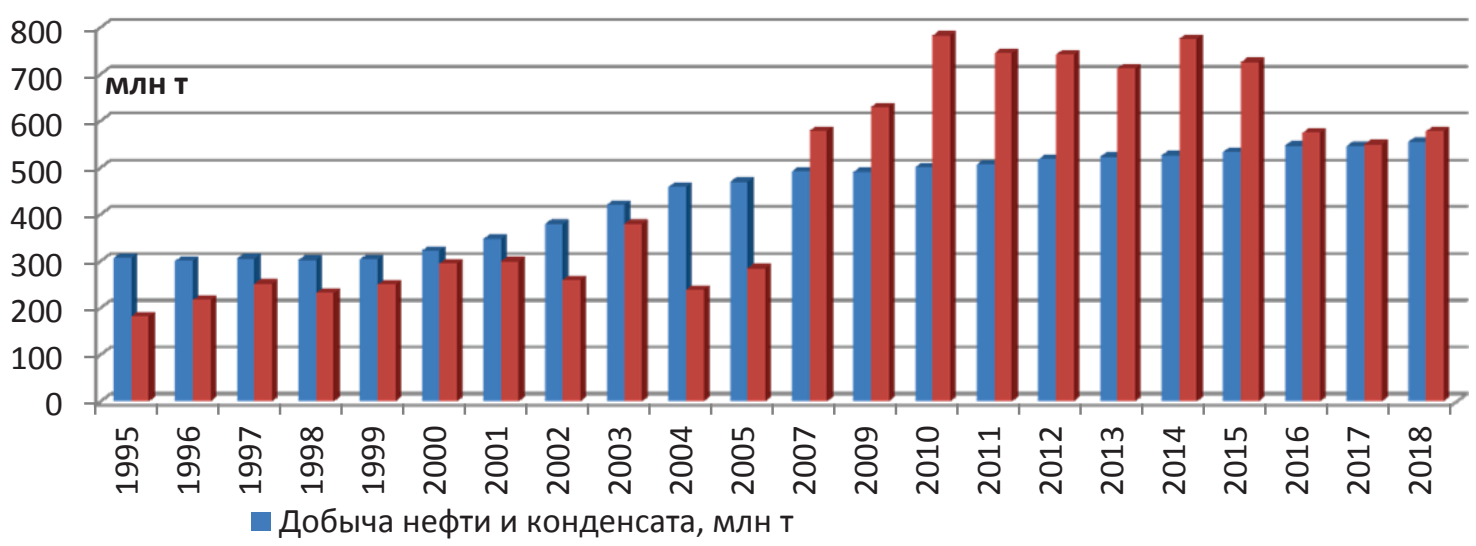

п Прирост запасов нефти и конденсата $A+B+C 1$, (2018 г. - AB $\left._{1} C_{1}\right)$ млн т

Pис. 1. Добыча и прирост запасов нефти и конденсата в России, млн $\mathrm{m}$

Fig. 1. Production and growth of oil and condensate reserves in Russia, million tons

марными запасами нефти $\mathrm{C}_{1}+\mathrm{C}_{2}-21,6$ млн т располагаются в Приволжском ФО. Открытия крупных месторождений в Западной Сибири становятся редкостью, поэтому событием является постановка на Государственный баланс Иртышского месторождения с запасами 21,4 млн т. В количественном плане открытий в Западной Сибири меньше, хотя она является основной кладовой УВ. Так, ее прогнозные ресурсы нефти составляют 24 млрд т против 21,38 остальных нефтегазоносных бассейнов РФ [4. С. 16]. Таким образом, актуализируется задача анализа эффективности геологоразведочных работ как основы воспроизводства ресурсной базы углеводородов в территориальном разрезе.

Необходимо заметить, что эффективность воспроизводства определяется комплексным воздействием различных факторов экономического, институционального, социально-политического и пространственно-геологического характера, что не сводит эффективность воспроизводства только к восполнению погашенных запасов. Воспроизводство - это циклический процесс поиска, разведки, разработки на основе принципов рационального недропользования, как следствие востребованы экономико-статистические методы, позволяющие оценить влияние макроэкономического, макроэнергетического, технологического окружения.

Целью данной научной работы является проведение сравнительной оценки эффективности воспроизводственных процессов на ресурсодобывающих территориях с учетом построения экономикоматематических моделей, основанных на применении непараметрических методов статистики.

\section{Материалы и методы}

Объектами исследования явиляются Республика Татарстан, ХМАО-Югра и Томская область, где НГК играет значительную роль в формировании ВРП. В то же время схожесть Томской области в геологическом плане с Республикой Татарстан, обладающей преимущественно мелкими и средни- ми месторождениями, и отличие от ХМАО-Югры, в котором сконцентрированы уникальные и крупные месторождения, а также отличие западносибирских субъектов РФ в транспортно-инфраструктурном и географо-климатическом от приволжских регионов делают данное исследование более объективным в контексте выявления негативно влияющих факторов на формирование устойчивых тенденций.

Основным источником информации явиляется официальная статистика государственных докладов исполнительных органов власти федерального и регионального уровня, региональных и отраслевых программных документов, министерств и ведомств РФ [4-7].

Основой выбора непараметрических методов исследования послужило, во-первых, отсутствие прямой функциональной зависимости между входными и выходными показателями блочной модели инвестиционного цикла, а во-вторых, возможность отследить рефлексию субъекта недропользования на происходящие изменения [8]. Алгоритм расчета и последовательность исследования представлены на рис. 2.

Выбор индекса производительности Малмквиста MPI (Malmquist productivity index) [9-15], на основе которого проводится расчет коэффициента динамической эффективности $\mathrm{F}$ по блокам инвестиционного цикла - геолого-технологическому, производственному, организационно-отраслевому, социально-экономическому, бюджетному и финансово-налоговому, был обусловлен тем, что данный индекс учитывает не только изменение местоположения самой границы эффективности, но и запаздывающее или догоняющее движение субъекта недропользования, т. е. его рефлексию на происходящие изменения, что наглядно иллюстрируется линейным трендом.

Расчет индекса производительности Малмквиста предполагает нахождение 4-компонентной меры эффективности посредством решения оптими- 
Методика оценки динамической эффективности блоков инвестиционного цикла воспроизводственных процессов

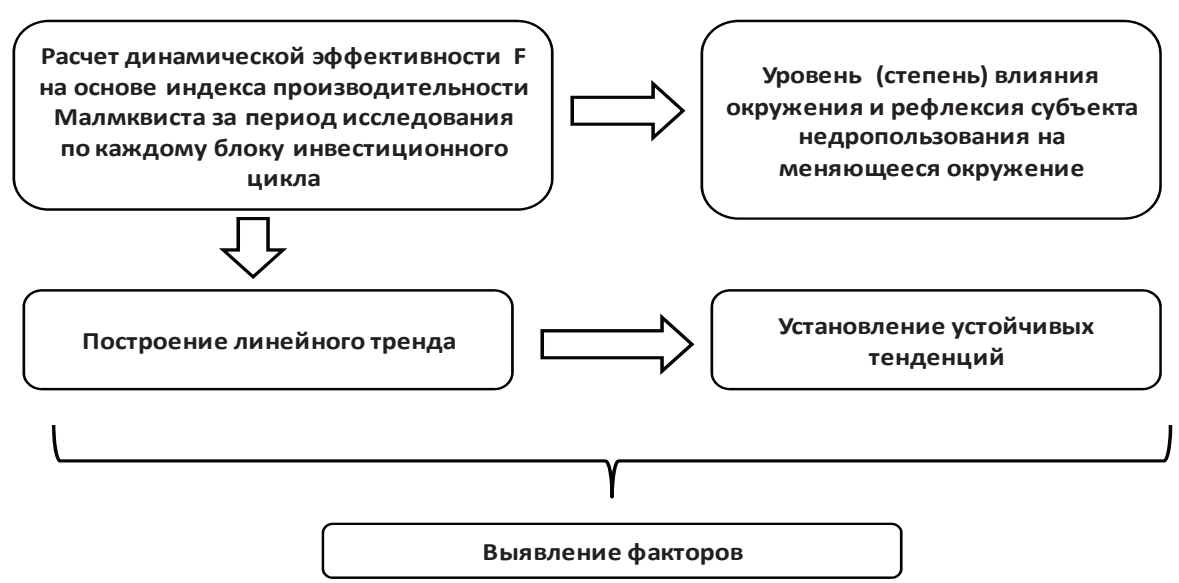

Рис. 2. методика исследования

Fig. 2. Research technique

зационных задач линейного программирования:

$$
F=\sqrt{\frac{k_{0}^{t}\left(I_{0}^{t+1}, R s_{0}^{t+1}\right)}{k_{0}^{t}\left(I_{0}^{t}, R s_{0}^{t}\right)} \cdot \frac{k_{0}^{t+1}\left(I_{0}^{t+1}, R s_{0}^{t+1}\right)}{k_{0}^{t+1}\left(I_{0}^{t}, R s_{0}^{t}\right)}},
$$

где $k_{0}^{t}\left(I_{0}^{t}, R s_{0}^{t}\right)$ и $k_{0}^{t+1}\left(I_{0}^{t+1}, R s_{0}^{t+1}\right)$ - меры эффективности объекта исследования с индексом 0, в моменты времени $t$ и $t+1$ рассчитаны посредством метода DEA (Data Envelopment Analysis) для модели, предполагаемой максимизацию выходного показателя (результата); $k_{0}^{t}\left(I_{0}^{t+1}, R s_{0}^{t+1}\right)$ - мера эффективности объекта исследования $j$ в момент времени $t$ относительно границы эффективности будущего периода $t+1 ; k_{0}^{t+1}\left(I_{0}^{t}, R s_{0}^{t}\right)$ - мера эффективности объекта исследования $j$ в момент времени $t+1$ относительно границы эффективности прошлого периода $t$; 0 - это индекс объекта исследования из множества $\{j=1, \ldots, J\}$, динамическая әффективность которого оценивается.

По значению $F$ можно судить о снижении $(F<1)$, постоянстве $(F=1)$ или увеличении $(F>1)$ эффективности объекта исследования в течение пары лет.

В случае нескольких пар лет на периоде исследования в работе [13] предложено оценивать долгосрочную динамику $F$ линейным трендом $\alpha t+b$ ( $\alpha>0$ определяет прогнозный прогресс, а $\alpha<0$ - peгресс). В рассматриваемой многостадийной модели инвестиционного цикла воспроизводства УВ второй год в одной стадии является первым в следующей стадии [8].

При расчете коэффициентов динамической эффективности воспроизводственных процессов императивом выступает идентичность выбранных показателей по каждому блоку и период исследования.

Результаты
Фрагмент показателей, выбранных для расчета коэффициента динамической эффективности по каждому блоку [8], представлен в табл. 1.

таблица 1. Таблица показателей

Table 1. Table of indicators

\begin{tabular}{|c|c|c|c|c|}
\hline 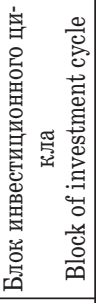 & & $\begin{array}{c}\text { Входные показатели } \\
\text { (I - ресурсы) } \\
\text { Input indicators } \\
\text { (I - resources) }\end{array}$ & & $\begin{array}{c}\text { Выходные показатели } \\
\text { (R - результаты) } \\
\text { Output indicators } \\
\text { (R-resources) }\end{array}$ \\
\hline \multirow{4}{*}{ 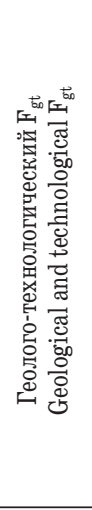 } & $I_{\text {comp }}$ & $\begin{array}{l}\text { Инвестиции в ГРР недро- } \\
\text { пользователей, млн р. } \\
\text { Investments in explora- } \\
\text { tion, mln rub. }\end{array}$ & \multirow{2}{*}{$\mathrm{R}$} & \multirow{2}{*}{$\begin{array}{l}\text { Прирост запасов, } \\
\text { млн т } \\
\text { Reserves growth, } \\
\text { mln tons }\end{array}$} \\
\hline & $\mathrm{Dr}$ & $\begin{array}{l}\text { Поисково-разведочное } \\
\text { бурение, тыс. } \mathrm{m}^{3} \\
\text { Prospecting-exploration } \\
\text { drilling, thousand } \mathrm{m}^{3}\end{array}$ & & \\
\hline & $2 \mathrm{D}$ & $\begin{array}{l}\text { 2D (МОГТ-2), пог. м } \\
\text { 2D seismic, linear meter }\end{array}$ & \multirow{2}{*}{\multicolumn{2}{|c|}{$\mid \begin{array}{l}\text { Коэффициент восполне- } \\
\text { ния добытых объемов } \\
\text { нефти приращенными } \\
\text { 3апасами } \\
\text { Replacement ratio of the } \\
\text { produced volumes of oil } \\
\text { by reserves }\end{array}$}} \\
\hline & $3 \mathrm{D}$ & $\begin{array}{l}\text { 3D (МОГТ-3), } \mathrm{kM}^{2} \\
\text { 3D seismic, } \mathrm{km}^{2}\end{array}$ & & \\
\hline \multirow{2}{*}{ 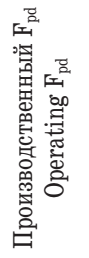 } & $\mathrm{R}$ & $\begin{array}{l}\text { Прирост запасов, млн т } \\
\text { Reserves growth, mln } \\
\text { tons }\end{array}$ & \multirow[b]{2}{*}{$\mathrm{Q}$} & \multirow{2}{*}{$\begin{array}{l}\text { Добыча, млн т } \\
\text { Production, mln tons }\end{array}$} \\
\hline & $\mathrm{Dr}_{\mathrm{pr}}$ & $\begin{array}{l}\text { Поисково-разведочное } \\
\text { бурение, тыс. }{ }^{3} \\
\text { Prospecting-exploration } \\
\text { drilling, thousand } \mathrm{m}^{3}\end{array}$ & & \\
\hline
\end{tabular}

Авторами исследовался период 2011-2016 гг. 
Таблица 2. Уравнения линейных трендов динамической эффективности F по блокал инвестиционного иикла воспроизводственных процессвв в нефтедобывающих субъектах $Р \Phi$

Table 2. Equations of linear trends of dynamic efficiency $F$ for the investment cycle blocks of reproduction in oil-producing regions of the Russian Federation

\begin{tabular}{|c|c|c|c|}
\hline \multirow[b]{2}{*}{$\begin{array}{c}\text { Субъект РФ } \\
\text { Constituent territory of the RF }\end{array}$} & \multicolumn{3}{|c|}{ Блок инвестиционного цикла/Block of investment cycle } \\
\hline & $\begin{array}{l}\text { Геолого-технологический } \mathrm{F}_{\mathrm{gt}} \\
\text { Geological and technological } \mathrm{F}_{\mathrm{gt}}\end{array}$ & $\begin{array}{l}\text { Производственный } \mathrm{F}_{\mathrm{pd}} \\
\text { Operating } \mathrm{F}_{\mathrm{pd}}\end{array}$ & $\begin{array}{l}\text { Организационно-отраслевой } \mathrm{F}_{\mathrm{oi}} \\
\text { Organizational and Industrial } \mathrm{F}_{\mathrm{pd}}\end{array}$ \\
\hline $\begin{array}{l}\text { Республика Татарстан } \\
\text { the Republic of Tatarstan }\end{array}$ & - & $1,0602-0,0216 * \mathrm{x}$ & $0,942+0,0201 * \mathrm{x}$ \\
\hline $\mathrm{XMA0/KhMAD}$ & $0,7906+0,0607 * \mathrm{x}$ & $1,3496-0,0851 * \mathrm{x}$ & $0,1408+0,3311 * x$ \\
\hline Томская область/Tomsk region & $2,3162-0,27 * \mathrm{x}$ & $2,7458-0,3209 * \mathrm{x}$ & $0,6056+0,0964 \% \mathrm{x}$ \\
\hline $\begin{array}{l}\text { Субъект РФ } \\
\text { Constituent territory of the RF }\end{array}$ & $\begin{array}{c}\text { Социально-экономический } \mathrm{F}_{\mathrm{se}} \\
\text { Social-economic } \mathrm{F}_{\mathrm{se}}\end{array}$ & $\begin{array}{l}\text { Бюджетный } \mathrm{F}_{\mathrm{b}} \\
\text { Budgetary } \mathrm{F}_{\mathrm{b}}\end{array}$ & $\begin{array}{c}\text { Финансово-налоговый } \mathrm{F}_{\mathrm{ft}} \\
\text { Financial and tax } \mathrm{F}_{\mathrm{ft}}\end{array}$ \\
\hline $\begin{array}{l}\text { Республика } \\
\text { Татарстан the Republic of Tatarstan }\end{array}$ & $1,372-0,0716 * \mathrm{x}$ & $0,7058+0,0495 * \mathrm{x}$ & $0,44+0,0318 * \mathrm{x}$ \\
\hline XMA0/KhMAD & $1,1192-0,0071 * \mathrm{x}$ & $2,2192-0,2628 * \mathrm{x}$ & $0,5543+0,0448 * \mathrm{x}$ \\
\hline Томская область/Tomsk region & $1,1466-0,0113 * \mathrm{x}$ & $1,4334-0,0909 * \mathrm{x}$ & $0,0643+0,0813 * \mathrm{x}$ \\
\hline
\end{tabular}

Здесь х показывает годы в следующем соответствии / $x$ shows the years: 1 - 2011 г., 2 - 2012 г., 3 - 2013 г., 4 - 2014 г., 5 - 2015 г., 6 - 2016 г.

Это связано с тем, что с 2016 г. действует другая классификация запасов и ресурсов нефти и горючих газов, ключевым критерием которых, помимо количественной оценки с точки зрения геологической изученности и технологической возможности их извлечения, является рентабельность их освоения, как следствие в 2016 г. к извлекаемым запасам относились категории $\mathrm{A}+\mathrm{B}+\mathrm{C}_{1}$, а в 2017 г. $\mathrm{A}+\mathrm{B}_{1}+\mathrm{C}_{1}[16]$. Следствием изменений стало практическое отсутствие статистических данных за 2017 г. по приросту запасов по многим субъектам РФ, либо подсчет в силу двухгодичности процесса ГРР (в первый год осуществляется завоз бурового оборудования, проведение сейсморазведки, а во второй год - поисково-разведочное бурение и подсчет запасов) осуществлялся на основе старой классификации. Таким образом, с целью соблюдения достоверности и корректности расчета геоло- го-технологической эффективности и объективности полученных результатов период исследования ограничен 2016 г.

Еще одним ограничением в модельных расчетах явиляются отсутствие официальных статистических данных по другим субъектам РФ - ВолгоУральской и Западно-Сибирской НГП, а также по другим годам по выбранным объектам исследования.

Проведенные расчеты коэффициентов динамической эффективности воспроизводственных процессов позволили построить уравнения линейных трендов (табл. 2).

Заметим, что все три региона имеют отрицательные $(\alpha<0)$ тренды (прогнозный регресс) по производственному $\left(\mathrm{F}_{\mathrm{pd}}\right)$ и социально-экономическому $\left(\mathrm{F}_{\mathrm{se}}\right)$ блокам, Томская область - еще и по геологотехнологическому $\left(\mathrm{F}_{\mathrm{g}}\right)$ и бюджетному $\left(\mathrm{F}_{\mathrm{b}}\right)$ блокам.
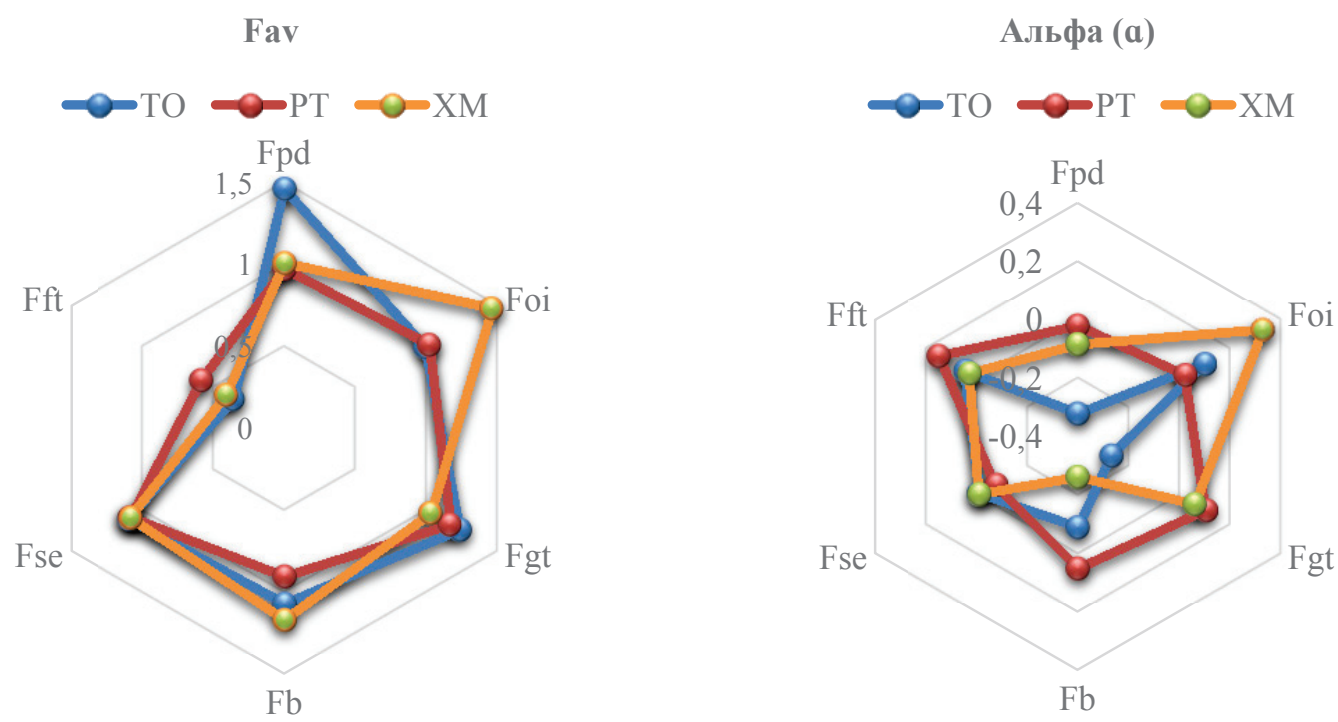

Pис. 3. Составные по регионам линейные графики эффективности (Fav, усредненной по времени исследования, - слева; Альфа ( $\alpha$ ) справа) в инвестииионном иикле

Fig. 3. Linear efficiency graphs composite by region (Fav, time-averaged study - on the left; Alpha - right) in the investment cycle 
Для полноты динамической картины воспроизводственного процесса наряду с $\alpha$ (Альфа) рассчитаны также Fav - усредненные по исследуемому периоду (рис. 3).

Согласно рис. 3 , например, все три региона испытывают снижение финансово-налоговой эффективности $\left(\mathrm{F}_{\mathrm{ft}}<1\right)$, но при этом демонстрируют прогнозный прогресс $(\alpha>0)$, особенно Республика Татарстан. А на примере XMAO можно говорить не только об увеличении организационно-отраслевой эффективности $\left(\mathrm{F}_{\text {оi }}>1\right)$, но и прогнозном прогрессе $(\alpha>0)$, то есть усилении увеличения этой эффективности.

Рис. 2 иллюстрирует наличие инвестиционного дестабилизатора воспроизводственных процессов, под которым авторы понимают механизм совокупного влияния институциональных и макроэкономических факторов, которое заключается в том, что минимальные налоговые расходы государства в части льготирования по НДПИ с целью интенсификации добычи ТрИЗ, а также низкие экспортные цены на нефть вследствие ситуации на мировом рынке дифференцированно влияют на инвестиционный потенциал недропользователей в субъектах РФ, что иллюстрируется нашим исследованием. В частности, в Республике Татарстан и ХМАО-Югра тренд динамической производственной эффективности $\left(\mathrm{F}_{\mathrm{pd}}\right)$ отрицателен. На недропользователей Томской области он оказывает более сильное влияние, о чем говорит практически отрицательная динамическая эффективность по геолого-технологическому блоку $\left(\mathrm{F}_{\mathrm{gt}}\right)$ и производственному блоку $\left(\mathrm{F}_{\mathrm{pd}}\right)$, что сдерживает развитие НГК, а следовательно, снижает темпы экономического роста. Далее, согласно модельным расчетам, прогнозируется значительное снижение доходов бюджетной системы. Что касается системы льготирования по НДПИ, то по Республике Татарстан прогнозируется снижение эффективности предоставляемых налоговых льгот. В результате можно наблюдать постепенное "сдувание» инвестиционного воспроизводственного цикла.

Основными причинами данной картины являются, по мнению авторов, производственные, инфраструктурные и географо-климатические условия, в которых осуществляют разработку и геологоразведочные работы недропользователи. Томскую область, как и ХМАО-Югра, отличают отсутствие круглогодичных дорог вследствие высокой заболоченности территорий данных субъектов и низкие температурные режимы. Однако влияние данного фактора по ХМАО-Югре нивелируется в определенной степени благодаря масштабности деятельности нефтегазовых компаний и сложившейся уникальности ресурсной базы в результате геологической истории Западно-Сибирской НГП. Так, стоимость прироста 1 т запасов в Томской области в среднем в два раза выше, чем в ХМАО-Югра, и в три раза выше, чем в субъектах РФ Приволжского ФО.

Важно отметить и другие аспекты стоимостных параметров ГРР. Так, чем выше разведанность, тем больше финансовых ресурсов необходимо для воспроизводства запасов. В частности, К.Н. Миловидов утверждает, что несопоставимы затраты на выявление $75 \%$ всех потенциальных ресурсов в новых нефтегазоносных районах, для подтверждения которых достаточно нескольких поисковых скважин, и оставшихся $25 \%$, которые являются более затратными [17. С. 91]. В частности, на подготовку 50 \% запасов необходимо в среднем $10 \%$ всех капиталовложений, 75 \% запасов - $25 \%$. Достижение $90 \%$ степени разведанности начальных суммарных ресурсов требует порядка $60 \%$ всех капиталовложений [17. С. 91]. Таким образом, учитывая степень разведанности, которая по Волго-Уральской НГП составляет 78 \%, а по ЗападноСибирской НГП - 54,8 \%, открытия месторождений нефти и газа в Западной Сибири являются более перспективными. Как следствие, недостаточность инвестиционного потенциала ГРР недропользователей, ведущих свою деятельность в специфических условиях, является сдерживающим фактором.

Таким образом, сформировавшийся и развивающийся инвестиционный дисбаланс между воспроизводством и добычей УВ как результат недофинансированности ГРР вследствие наличия инвестиционного дестабилизатора стал одним из факторов низкой обеспеченности запасами нефти, отраженной в вышеназванной Стратегии.

\section{Выводы}

Полученные результаты позволяют выделить следующие основные факторы, повлиявшие на формирование устойчивых тенденций.

1. Предлагаемая методика оценки воспроизводственных процессов на всех этапах инвестиционного цикла позволяет отразить взаимосвязь всех ключевых показателей развития нефтегазовой отрасли путем расчета динамической эффективности этапов воспроизводственного процесса.

2. Влияние внешней среды на недропользователей вследствие стагнации цен на мировом рынке нефти на недропользователей усиливается под действием организационно-экономического механизма в системе недропользования и специфических условий деятельности (производственноинфраструктурные, географо-климатические), что наиболее наглядно в Томской области.

3. Решение проблемы хронической недофинансированности ГРР видится авторами в использовании механизмов государственно-частного партнерства и активизации деятельности юниорных компаний $[18,19]$.

4. Сохраняющаяся политика интенсификации добычи нефти, поддерживаемая системой налогового льготирования добычи трудноизвлекаемых запасов нефти [20, 21], обусловливает отрицательный прогноз перспектив добычи в средне- и долгосрочной перспективе без достаточной обеспеченности запасами. 
5. Политика стимулирования добычи ТрИЗ лежит в основе различия во взглядах недропользователя и государства на целевое содержание льготы по НДПИ. Недропользователь видит компенсационную сущность налоговой льготы на извлечение ТрИЗ, а государство рассматривает ее в том числе и как дополнительный инвестиционный потенциал ГРР.

6. Льготы по налогу на прибыль в виде прикладываемого к расходам на освоение природных ресурсов коэффициента, равного 1,5, предоставляются для геологического изучения, включающего поиски и оценку новых морских месторождений УВ. Однако желательны аналогичные льготы и для малых недропользователей, осуществляющих свою деятельность на территории Западной Сибири, что позволит увеличить инвестиционный потенциал ГРР, а следовательно, степень разведанности.

7. Роль воспроизводства ресурсов УВ снижается в формировании ВРП, что является следствием утраты организационной модели ведения ГРР, предполагавшей размещение нефтегазоразведочных экспедиций в соответствии с картой нефтегазоносности, которые вносили существенный вклад в создание добавленной стоимости.

8. Стопроцентное изъятие доходов от добычи нефти и газа в федеральный бюджет влияет наиболее сильно на снижение инвестиционного потенциала в Томской области, так как масштабы

\section{СПИСОК ЛИТЕРАТУРЫ}

1. Стратегия развития минерально-сырьевой базы Российской Федерации до 2035 года (утв. Распоряжением Правительства РФ от 22.12.2018 г. № 2914-p). M., 2018. URL: http://government.ru/docs/35247/ (дата обращения: 29.03.2019).

2. Нефтяная промышленность исторически главных центров Волго-Уральской нефтегазоносной провинции, элементы их истории, ближайшие и отдаленные перспективы / А.Э. Конторович, Л.В. Эдер, И.В. Филимонова, М.В. Мишенин, В.Ю. Немов // Геология и геофизика. - 2016. - Т. 57. - № 12. C. 2097-2114. DOI: $10.15372 /$ GiG20161201.

3. Current state and problems of integrated development of mineral resources base in Russia / I.V. Filimonova, L.V. Eder, M.V. Mishenin, T.M. Mamakhatov // IOP Conference Series: Earth and Environmental Science. - 2017. - V. 84. - № 1. P. 1-5. DOI: $10.1088 / 1755-1315 / 84 / 1 / 012011$.

4. Государственный доклад «0 состоянии и использовании минерально-сырьевых ресурсов Российской Федерации в 2016 и 2017 годах" / гл. ред. Е.А. Киселев. - М., 2018. - 370 с.

5. Государственные доклады «0 состоянии природных ресурсов и об охране окружающей среды Республики Татарстан” за 2005-2014 гг. URL: http://eco.tatarstan.ru/gosdoklad.htm (дата обращения: 04.03.2019).

6. Государственные доклады «0 состоянии и охране окружающей среды Томской области" за 2003-2016 гг. URL: https://ogbu.green.tsu.ru/? page_id=1456 (дата обращения: 12.03.2019).

7. Доклады «0б экологической ситуации в Ханты-Мансийском автономном округе - Югре» за 2008-2016 гг. URL: https://prirodnadzor.admhmao.ru/doklady-i-otchyety/ (дата обращения: 12.03.2018). деятельности добывающих предприятий таковы, что доходы, аккумулируемые в территориальном бюджете, несопоставимы с поступлениями по НДПИ в федеральный бюджет. Это является значимым фактором при реализации программ социально-экономического развития, в частности строительства транспортной логистики в северных добывающих районах Томской области.

\section{Заключение}

Проведение ГРР является основой для комплексного освоения и развития регионов и сохранения минерально-сырьевой безопасности России, а следовательно, способствует укреплению ее экономических позиций на мировом рынке. Таким образом, проведенное исследование является дополнительным аргументом необходимости корректировки государственного регулирования в недропользовании с целью стимулирования стратегических важных видов полезных ископаемых. Необходимо развивать механизмы государственного и частного финансирования и финансово-налогового стимулирования.

Работа выполнена при финансовой поддержке РФФИ, грант 18-010-00660 A «Концептуальные подходы к парадигле устойчивого и сбалансированного недропользования области с учетом специфики минерально-сырьевой базы и отраслевой структуры в иелях обеспечения долгосрочного социально-экономического роста нефтедобывающего региона».

8. Шарф И.В. Методологические подходы к оценке эффективности воспроизводства запасов углеводородов // Фундаментальные исследования. - 2019. - № 2. - С. 43-48. URL: http://fundamental-research.ru/ru/article/view? id=42413 (дата обращения: 14.04.2019),

9. Alimohammadlou M., Mohammadi S. Evaluating the productivity using Malmquist index based on double frontiers data // Procedia - Social and Behavioral Sciences. - 2016. - № 230. P. 58-66. D0I: 10.1016/j.sbspro.2016.09.008.

10. Azad A.K., Masum A.K., Haque S. Use of Circular Malmquist Index (CMI) and Variable Returns to Scale (VRS-MI) in Productivity Measurement - a Comparative Study // International Journal of Ethics in Social Sciences. - 2014. - V. 2. - № 2. - P. 69-76.

11. Bao H., An X. Reliability Test on Oil Field Efficiency with DEA // Energy Procedia. - 2011. - V. 5. - P. 1473-1477. DOI: 10.1016/j.egypro.2011.03.252.

12. Malmquist S. Index numbers and indifference surfaces // Trabajos de Estatistica. - 1953. - V. 4. - № 2. - P. 209-242. DOI: $10.1007 / \mathrm{BF} 03006863$.

13. Jafari Y. Malmquist Productivity Index for Multi Time Periods // International Journal of Data Envelopment Analysis. - 2014. V. 2. - № 1. - P. 315-322.

14. Productivity Growth, Technical Progress, and Efficiency Changes in Industrialised Countries / R. Fare, S. Grosskopf, M. Norris, Z. Zhang // American Economic Review. - 1994. - V. 84. № 1. - P. 66-83.

15. Tohidi G., Razavyan S. A circular global profit Malmquist productivity index in data envelopment analysis // Applied Mathematical Modelling. - 2013. - V. 37. - № 1-2, - P. 216-227. DOI: 10.1016/j.apm.2012.02.026. 
16. Шарф И.В. Экономические аспекты классификации запасов углеводородов // Электронный научный журнал «Нефтегазовое дело». - 2017. - № 1. - С. 236-254. D0I: 10.17122/ogbus2017-1-236-254.

17. Миловидов К.Н. Критерии и методы оценки әффективности воспроизводства запасов нефти и газа. - М.: Недра, 1989. $224 \mathrm{c}$.

18. New directions for sustainable development of oil and gas industry of Russia: Innovative strategies, regional smart specializations, public-private partnership / L.V. Eder, I.V. Filimonova, I.V. Provornaya, A.V. Komarova, S.M. Nikitenko // Surveying Geology and Mining Ecology Management: International Multidisciplinary Scientific GeoConference. - 2017. - V. 17. - № 15. P. 365-372. DOI: $10.5593 /$ sgem $2017 \mathrm{H} / 15 / \mathrm{S} 06.046$.
19. Kushnir M.A., Kushnir V.Y. Effect of a public-private partnership on investment attractiveness of gold mining projects // Mining Informational and Analytical Bulletin. - 2019. - Iss. 1. P. 200-207. DOI: 10.25018/0236-1493-2019-01-0-200-207

20. Grinkevich L.S., Sharf I.V., Borzenkova D.N. Tax incentives as the tool for stimulating hard to recover oil reserves development // IOP Conference Series: Earth and Environmental Science. 2015. - V. 27. - № 11. - P. 1-5. DOI: $10.1088 / 1755-1315 /$ $27 / 1 / 012079$.

21. Sabitova N.M., Shavaleyeva Ch.M. Oil and gas industry and risks in the Russian Federation budget system // Oil Industry - 2018. Iss. 4. - P. 12-15. DOI: 10.24887/0028-2448-2018-4-12-15.

Поступила 18.06.2019 2.

\section{Информация об авторах}

Шарф И.В., кандидат экономических наук, доцент отделения нефтегазового дела Инженерной школы природных ресурсов Национального исследовательского Томского политехнического университета.

Михальчук A.A., кандидат физико-математических наук, доцент отделения математики и информатики Школы базовой инженерной подготовки Национального исследовательского Томского политехнического университет.

Филимонова И.В., доктор экономических наук, ведущий научный сотрудник Центра экономики недропользования Института нефтегазовой геологии и геофизики им. А.А. Трофимука CO PAН. 


\title{
DYNAMIC EFFECTIVENESS OF REPRODUCTION IN RESOURCE PRODUCING REGIONS
}

Irina V. Sharf',

irina sharf@mail.ru

\author{
Alexander A. Mikhalchuk', \\ aamih@tpu.ru \\ Irina V. Filimonova ${ }^{2}$, \\ filimonovaiv@list.ru \\ 1 National Research Tomsk Polytechnic University, \\ 30, Lenin Avenue, Tomsk, 634050, Russia. \\ 2 Trofimuk Institute of Petroleum Geology and Geophysics SB RAS, \\ 3, Ac. Koptyug avenue, Novosibirsk, 3630090, Russia.
}

The relevance of the research is caused by deterioration of hydrocarbon resource base both in quality and quantity. The positive dynamics of reproduction is a basis for sustainable long-term operation of oil and gas sector and social-economic development of resource producing regions. Due to the lack of direct functional dependence in the process the research methods that would allow revealing negative factors and trends are required at all reproduction stages of investment cycle. These factors have resulted from changes taking place in hydrocarbon market and government control in subsurface use.

The aim of the research is the comparative assessment of reproduction effectiveness in resource producing regions taking into account economic-mathematical models based on the nonparametric statistical techniques.

Object: raw mineral base of resource producing regions of the Russian Federation.

Methods: regression, Malmquist Productivity Index.

Results. The paper presents characteristics of general trends in resource and oil reserve reproduction in Russia reflecting qualitative and quantitative characteristics of oil resource base. The research methods based on developing dynamic effectiveness is considered. It demonstrates the tendency of subsurface use entities' response to the changes in macroeconomic environment as well as in the subsurface use sector in terms of tax incentives. Block model of investment cycle combined with the following blocks - geological-engineering, production, management-industrial, social-economic, budget, tax - is the technological tool of assessing reproduction at all stages of investment cycle. It allows us to show the interaction of all key indicators in petroleum industry development. Modelling makes it possible to reveal an investment destabilizer in the form of combined effect of management-economic mechanism in subsurface use in terms of tax incentives and price parameters in the oil world market. In this context, the most intensive effect is observed in Tomsk region.

\section{Key words:}

Oil, reserves, Malmquist Index, dynamic effectiveness, investment reproduction cycle.

The research is supported by RFFR grant 18-010-00660A «Conceptual approaches to the paradigm of sustainable and balanced subsoil use taking into account mineral base specificity and industry structure to provide long-term social-economic growth of the oil-producing region».

\section{REFERENCES}

1. Strategiya razvitiya mineralno-syrevoy bazy Rossiyskoy Federatsii do 2035 goda. Utv. Rasporyazheniem Pravitelstva $R F$ ot 22.12.2018 g. № 2914-r [The strategy for development of the mineral resource base of the Russian Federation until 2035. Approved by the Order of the Government of the Russian Federation of 22.12.2018, No. 2914-p]. Moscow, 2018. Available at: http://government.ru/docs/35247/ (accessed 29 March 2019).

2. Kontorovich A.E., Eder L.V., Filimonova I.V., Mishenin M.V., Nemov V.Y. Oil industry of major historical centers of the VolgaUral petroleum province: past, current state, and long-run prospects. Russian Geology and Geophysics, 2016, vol. 57, no. 12, pp. 1653-1667. In Rus.

3. Filimonova I.V., Eder L.V., Mishenin M.V., Mamakhatov T.M. Current state and problems of integrated development of mineral resources base in Russia. IOP Conference Series: Earth and Environmental Science, 2017, vol. 84, no. 1, pp. 1-5. DOI: $10.1088 / 1755-1315 / 84 / 1 / 012011$.

4. Gosudarstvenny doklad «O sostoyanii i ispolzovanii mineralno-syrevykh resursov Rossiyskoy Federatsii v 2016 i 2017 godakh" [State report «0n the state and use of mineral resources of the
Russian Federation in 2016 and 2017»]. Ed. by E.A. Kiselev. Moscow, 2018. 370 p.

5. Gosudarstvennye doklady «0 sostoyanii prirodnykh resursov $i$ ob okhrane okruzhayushchey sredy Respubliki Tatarstan" za 2005-2014 gg. [State reports «0n the state of natural resources and on environmental protection of the Republic of Tatarstan" for 2005-2014]. Available at: http://eco.tatarstan.ru/gosdoklad.htm (accessed 12 March 2019).

6. Gosudarstvennye doklady «0 sostoyanii $i$ okhrane okruzhayushchey sredy Tomskoy oblasti» za 2003-2016 gg. [State reports "On the condition and environmental protection of the Tomsk region" for the period of 2003-2016.] Available at: https://ogbu.green.tsu.ru/? page_id=1456 (accessed 12 March 2019).

7. Doklady «Ob ekologicheskoy situatsii v Khanty-Mansiyskom avtonomnom okruge - Yugre» za 2008-2016 gg. [Reports «On the environmental situation in the Khanty-Mansiysk Autonomous Okrug-Ugra" for 2008-2016]. Available at: https://prirodnadzor.admhmao.ru/doklady-i-otchyety/ (accessed 12 March 2019).

8. Sharf I.V. Methodological Approaches to Assess Reproduction Efficiency of Hydrocarbon Reserves. Fundamental research, 
2019, no. 2, pp. 43-48. In Rus. Available at: http://fundamentalresearch.ru/ru/article/view? id=42413 (accessed 14 April 2019).

9. Alimohammadlou M., Mohammadi S. Evaluating the productivity using Malmquist index based on double frontiers data. Procedia - Social and Behavioral Sciences, 2016, no. 230, pp. 58-66. DOI: $10.1016 / j . s b s p r o .2016 .09 .008$.

10. Azad A.K., Masum A.K., Haque S. Use of Circular Malmquist Index (CMI) and Variable Returns to Scale (VRS-MI) in Productivity Measurement- a Comparative Study. International Journal of Ethics in Social Sciences, 2014, vol. 2, no. 2, pp. 69-76.

11. Bao H., An X. Reliability Test on Oil Field Efficiency with DEA. Energy Procedia, 2011, vol. 5, pp. 1473-1477. DOI: 10.1016/j.egypro.2011.03.252.

12. Malmquist S. Index numbers and indifference surfaces. Trabajos de Estatistica, 1953, vol. 4, no. 2, pp. 209-242. DOI: 10.1007/BF03006863.

13. Jafari Y. Malmquist Productivity Index for Multi Time Periods. International Journal of Data Envelopment Analysis, 2014, vol. 2, no. 1, pp. 315-322.

14. Fare R., Grosskopf S., Norris M., Zhang Z. Productivity Growth, Technical Progress, and Efficiency Changes in Industrialised Countries. American Economic Review, 1994, vol. 84, no. 1, pp. $66-83$.

15. Tohidi G., Razavyan S. A circular global profit Malmquist productivity index in data envelopment analysis. Applied Mathematical Modelling, 2013, vol. 37, no. 1-2, pp. 216-227. DOI: 10.1016/j.apm.2012.02.026.

\section{Information about the authors}

Irina V. Sharf, Cand. Sc., associate professor, National Research Tomsk Polytechnic University.

Alexander A. Mikhalchuk, Cand. Sc., associate professor, National Research Tomsk Polytechnic University.

Irina V.Filimonova, Dr. Sc., leading researcher, A.A. Trofimuk Institute of Petroleum Geology and Geophysics SB RAS.
16. Sharf I.V. Economic Aspects of Hydrocarbon Reserves Classification. Oil and Gas Business, 2017, no. 1, pp. 236-254. In Rus. D0I: $10.17122 /$ ogbus-2017-1-236-254.

17. Milovidov K.N. Kriterii i metody otsenki effektivnosti vosproizvodstva zapasou nefti i gaza [Criteria and methods for evaluating the efficiency of reproduction of oil and gas reserves]. Moscow, Nedra Publ., 1989. 224 p.

18. Eder L.V., Filimonova I.V., Provornaya I.V., Komarova A.V., Nikitenko S.M. New directions for sustainable development of oil and gas industry of Russia: Innovative strategies, regional smart specializations, public-private partnership. International Multidisciplinary Scientific GeoConference. Surveying Geology and Mining Ecology Management, 2017, vol. 17, no. 15, pp. 365-372. DOI: $10.5593 /$ sgem $2017 \mathrm{H} / 15 / \mathrm{S} 06.046$.

19. Kushnir M.A., Kushnir V.Y. Effect of a public-private partnership on investment attractiveness of gold mining projects. $\mathrm{Mi}$ ning Informational and Analytical Bulletin, 2019, Iss. 1, pp. 200-207. DOI: 10.25018/0236-1493-2019-01-0-200-207

20. Grinkevich L.S., Sharf I.V., Borzenkova D.N. Tax incentives as the tool for stimulating hard to recover oil reserves development. IOP Conference Series: Earth and Environmental Science, 2015, vol. 27, no. 11, pp. 1-5. DOI: 10.1088/1755-1315/27/1/012079.

21. Sabitova N.M., Shavaleyeva Ch.M. Oil and gas industry and risks in the Russian Federation budget system. Oil Industry, 2018, Iss. 4, pp. 12-15. DOI: 10.24887/0028-2448-2018-4-12-15.

Received: 18 June 2019. 